\title{
THE RELATION BETWEEN MEDIA EXPOSURE, RISK BEHAVIOUR AND ANXIETY IN ADOLESCENTS DURING THE COVID-19 PANDEMIC
}

\author{
Goran Livazović, Karlo Bojčić \\ Josip Juraj Strossmayer University of Osijek, Republic of Croatia
}

\begin{abstract}
This report is focused on a theoretical and empirical analysis of an on-line questionnaire implemented with 246 adolescent participants from Croatia in 2020 during the COVID-19 pandemic. The aim of the study was to analyse the relation between the COVID-19 pandemic related fear and risk behaviour, anxiety and depression in adolescents, including the importance of sociodemographic traits, family/school/peer relationships and media use as risk-protective factors. The research was implemented during the March and April 2020 lockdown in Croatia with participants aged from 18-35 years old. The questionnaire consisted of 5 major parts: socio-demographic measures; media use and interests; Mean world syndrome; risk behaviour; and 2 standardized scales on anxiety and depression with a high validity of the Cronbach's alpha coefficients ranging from $a=.81$ to $a=.94$. Correlation analysis demonstrated significant positive relations between COVID-19 media exposure, risk behaviour and anxiety or depression. Our regression analysis established positive moderate predictive relations between risk behaviour, anxiety and depression $(p<.01)$. No significant effects for risk behaviour in relation to the participants' sociodemographic traits were found.
\end{abstract}

Keywords: adolescents, anxiety, COVID-19, depression, media, risk behaviour.

\section{Introduction}

The ongoing COVID-19 pandemic had important personal and social effects on the population. The fast spread and panic induced by the virus resulted in massive anxiety all over the world, and focused information-seeking attention on media during the period of social isolation. Studies have emphasized the impact on the psychological well-being of most vulnerable groups, including children and the youth, as well as a number of families, professional workers and the general public exposed to an increased risk of developing post-traumatic stress disorder, anxiety, 
depression or various risky behaviours (Saladino et al., 2020). Adolescence in particular, is usually associated with high-risk activities, and while some risk-taking behaviours are considered to be normative in youth, research has indicated an association between risky behaviours and mental problems with poorer health and emotional outcomes in adulthood (Moffitt et al., 2002; Sourander et al., 2007; Soleimani et al., 2017). Responsible and safe actions during pandemics usually include two broad categories of behaviours- avoidant actions such as staying at home, social distancing or avoiding public transportation, and preventive behaviours like washing hands or using sanitizers. Based on current evidence from past pandemics, the level of both avoidant and preventive behaviours is related to personal factors. Being female, older, having small children at home and higher educational degrees, increases the level of safe practices (Betancourt et al., 2016; Paek \& Hove, 2017; Wellman et al. 2018; all cited in Mohammadi et al., 2020).

Both inadequate or excessive levels of perceived risk are problematic, as low levels of contributed risk significantly decrease the likelihood of following necessary safety protocols, while high levels of contributed risk increase the proportion of mental health problems including anxiety, stress and depression (Asmundson et al., 2010; Blakey \& Abramowitz, 2017). Evidence suggests that risk-taking behaviour is influenced by emotional states, thus relating social anxiety to both risk-avoidant and risk-seeking decision making. Highly stressful situations can influence the decisions individuals make (Loewenstein et al., 2001), as evidence suggests that risk-taking behaviour is influenced by negative affective states such as fear, disgust, or anger (Lerner \& Keltner, 2000; 2001; as cited in Reynolds et al. 2013). The relationship is, however, complex, as stress can recruit cognitive resources for emotion regulation and divert away from the inhibitory processes necessary to avoid risky behaviour, resulting in more risk taking (Baumeister et al., 2007). Alternatively, engagement in risky behaviour can serve as a form of negative reinforcement, thus reducing distress associated with the social anxiety (Baker et al., 2004). For instance, Busse et al. (2021) reported being female, younger age, being bored, not having a trusted person and depressive symptoms were factors associated with a change in health-related behaviour. They identified five substance use behavioural profiles, which remained fairly unchanged during the pandemic: $61 \%$ of students consumed alcohol, $45.8 \%$ binge drank, $19.4 \%$ smoked and $10.8 \%$ used cannabis. While smoking and cannabis use remained unchanged during the COVID-19 pandemic, 24.4\% reported a decrease in binge drinking, while 5.4\% reported an increase. 30.6\% reported an increase and $19.3 \%$ reported a decrease in vigorous physical activity (Busse et al., 2021). 
Another stress inducing element is related to the theory behind the perception of fear and anxiety cultivation by the media, explaining how the more people "consume" the world of the mass media, the more they accept that social reality as credible, consequently experiencing more feelings of fear and anxiety, overemphasizing criminality or the chances of becoming a victim, even walking alone at night (Gerbner et al., 1978; Gerbner, 1998). Modern cultures tend to regularly confront the public with mass media global disaster or crime images and stories, in return fuelling overestimation and misrepresentation of surrounding dangers. However, if horrible incidents are overrepresented, the public might assume the world is an unforgivable place (Altheide, 1997, as cited in Klinkenberg, 2015:1), thus enhancing their sense or fear of victimization (Gerbner, 1978; as cited in Klinkenberg, 2015:1). This phenomenon is called the Mean world syndrome. When discussing the importance of media and the Mean world syndrome in relation to anxiety and stress, studies have established mixed findings. The Longitudinal Aging Study Amsterdam (LASA) with 1.536 participants found that reading newspapers, as well as Internet use decreases anxiety and fear, whereas television viewing increases them (Klinkenberg, 2015). Mass media use had a negative influence on feeling unsafe, so media users and those listening to the radio or watching sports were less likely to feel afraid in their neighbourhood at night, while those who watched the news and music clips on the television were more likely to be afraid (Klinkenberg, 2015).

The aim of the present study is to analyse the correlation between the COVID-19 pandemic related fear and risk behaviour, anxiety and depression in adolescents, including the importance of sociodemographic traits and media use as risk-protective factors. Our main hypothesis is that there is a statistically significant correlation between COVID-19 media exposure with anxiety, depression, fear and risky behaviour. Our second hypothesis is that sociodemographic traits have a significant role in risk behaviour in adolescents.

\section{Method}

\section{Measures and data collection}

The research was implemented via an online survey during the March and April 2020 lockdown in Croatia with students from the University in Osijek. The questionnaire consisted of 5 major parts.

a) The first part had questions on sociodemographic traits (sex, age, academic success, father's level of education, mother's level of education, family income status).

b) The second part had a non-standardized 15 item scale with questions specifically related to COVID-19 media exposure (i. e. television, radio, 
newspapers, web portals, social networks...), with five points (1-never, 2-once or twice in a month, 3-once a week, 4-several times a week, 5-daily). The 15 items were computed and transformed into a new composite variable named "COVID-19 media exposure" with consequent reliability analysis showing a good Cronbach's alpha coefficient $(\alpha=.76)$.

c) The third part consisted of 24 non-standardized items on a 5-point Likert scale ( 1 - never, 2 - rarely, 3 - sometimes, 4 - often, 5 - always) with Mean world syndrome questions about the participant's fears (i. e. I'm afraid someone will attack me on the street at night; I'm afraid someone will kidnap me or my child; I'm afraid to talk to strangers...) that was computed and transformed into a new composite variable named "Mean world syndrome" with a satisfactory Cronbach's alpha coefficient $(\alpha=.85)$.

d) The fourth part consisted of a non-standardized 24 item scale with questions about participant's risk behaviour since the beginning of the COVID-19 pandemic (i. e. I drink alcohol more often than before the pandemic; I steal more than in the pre-pandemic period; I use physical violence to solve problems more often than before the pandemic...). The 24-item scale was computed into a new composite variable named "Risk behaviour" with a satisfactory Cronbach's alpha coefficient $(\alpha=.80)$.

e) The fifth part consisted of standardized scales on anxiety (Anxiety Sensitivity Index, ASI, Reiss et al., 1986) and depression (Depression Anxiety Stress Scales, DASS; Lovibond \& Lovibond, 1995). The implemented scales demonstrated high reliability and validity, with Cronbach's alpha coefficients ranging from $\alpha=.81$ to $\alpha=.94$. The ASI is a self-reported measure on fear of different anxiety symptoms (Reiss et al., 1986). It consists of 16 items on anxiety symptoms, with answers on a 5-point scale (from "very little" - 0, to "very much" - 4). The total score is the sum of scores on individual items and varies between 0 and 64. The DASS is a set of three self-reported scales designed to measure the emotional states of depression, anxiety and stress. The 4-point rating scale varies from 0 - "Did not apply to me at all" to 3 - "Applied to me very much or most of the time". Each of the three subscales achieved satisfactory Cronbach's alpha coefficients (depression $\alpha=.88$, anxiety $\alpha=.84$, and stress $\alpha=.89$ ).

The data was processed using SPSS (v20.0.0) with descriptive and inferential statistical procedures: correlation and a 3-model hierarchical regression analysis. The first model consisted of sociodemographic traits, the second encompassed stress, anxiety and depression, while the third model consisted of COVID-19 media exposure and the Mean world syndrome. 


\section{Participants}

A total of 246 students participated in the online survey, 213 females (87\%) and 33 males (13\%). The sample age mean was 21.98. They had a 4.1 GPA with $28 \%(n=69)$ achieving an A (excellent), $52.8 \%(n=130)$ achieving a B (very good), $17.5 \%(n=43)$ achieving a C (good) and $0.2 \%$ $(n=2)$ that failed class (F). Participants reported that $64 \%(n=156)$ of their fathers completed elementary school or high school, while $36 \%$ ( $n=88)$ had college or university education. Some $61 \%(n=148)$ of mothers finished elementary or high school, 39\% $(n=96)$ had college or university education. A total of 38 (15.4\%) participants reported a monthly family income up to $660 €$ (up to 5000 Croatian kuna (kn), 103 (41.9\%) between $661 €$ and $1320 €(5001-10000 \mathrm{kn}), 67(27.2 \%)$ had a monthly income between $1321 €$ and $1980 €(10001-15000 \mathrm{kn})$, and 38 (15.4\%) reported an income of $1981 €$ and more (over $15001 \mathrm{kn}$ ).

\section{Results}

The means and standard deviations of the DASS subscales achieved in our study are $M=6.53$ ( $S D=5.04$ ) on stress, $M=3.34$ ( $S D=4.03$ ) on anxiety, and $M=5.18(S D=4.71)$ on depression. The means and standard deviations of the ASI achieved in our study are $M=24.51(S D=12.46)$. These results are derived from this study and do not correspond to the population levels in the Republic of Croatia.

When analysing COVID-19 media exposure, websites were the most popular sources $(M=3.87 ; S D=1.22)$, followed by information received from family members, friends, acquaintances or colleagues $(M=3.39 ; S D=1.49)$, via television $(M=2.97 ; S D=1.73)$ and Facebook $(M=2.47 ; S D=1.69)$.

Our results (Table 1) show a very weak positive correlation between the COVID-19 media exposure and the Anxiety Sensitivity Index $(p<.01)$, and a weak positive correlation between the COVID-19 media exposure and the Mean world syndrome $(p<.05)$. There is a very weak positive correlation between ASI and risk behaviour $(p<.05)$, and a moderate to strong positive correlation between DASS subscales of depression / anxiety/stress, and the Mean world syndrome with ASI $(p<.001)$. There is a weak to strong positive correlation between ASI, risk behaviour and the Mean world syndrome with all three DASS subscales $(p<.001)$. The participants also reported a positive weak correlation between risk behaviour and the Mean world syndrome $(p<.05)$.

Our regression analysis results demonstrate moderate positive relations between risk behaviour, anxiety and depression ( $\mathrm{p}<.01$ ) (Table 2). No significant predictive effects were established for sociodemographic traits or COVID-19 media exposure. 
Table 1. Correlation matrix on risk behaviour, stress, anxiety, mean world syndrome and media exposure $(n=245)$

\begin{tabular}{|c|c|c|c|c|c|c|c|}
\hline Variable & 1 & 2 & 3 & 4 & 5 & 6 & 7 \\
\hline 1. COVID-19 media exposure & 一 & $.17^{* *}$ & .09 & .08 & -.00 & -.08 & $.15^{*}$ \\
\hline 2. ASI & & - & $.57^{*+\ldots+4}$ & $.64^{* * * *}$ & $.46^{* * * *}$ & $.16^{*}$ & $.69^{* * *}$ \\
\hline 3. DASS Stress & & & - & $.74^{* * *}$ & $.73^{* * *+}$ & $.22^{* * * *}$ & $.52^{* * *}$ \\
\hline 4. DASS Anxiety & & & & - & $.64^{* * *}$ & $.31^{* * * *}$ & $.55^{* * *}$ \\
\hline 5. DASS Depression & & & & & - & $.32^{* * * *}$ & $.40^{* * *}$ \\
\hline 6. Risk behaviour & & & & & & - & $.15^{*}$ \\
\hline 7. Mean world syndrome & & & & & & & - \\
\hline
\end{tabular}

Note: $p<.05^{*} ; p<.01^{* *} ; p<.001^{* * *}$

Table 2. Regression analysis on risk behaviour $(n=245)$

\begin{tabular}{|c|c|c|c|c|c|c|c|c|c|c|c|c|}
\hline \multirow[t]{2}{*}{$\begin{array}{l}\text { Risk } \\
\text { behaviour }\end{array}$} & \multicolumn{4}{|c|}{$\begin{array}{l}\text { Model } 1 \text { (soc.-demo. } \\
\text { characteristics) }\end{array}$} & \multicolumn{4}{|c|}{$\begin{array}{l}\text { Model } 2 \text { (stress, } \\
\text { anxiety and } \\
\text { depression) }\end{array}$} & \multicolumn{4}{|c|}{$\begin{array}{l}\text { Model } 3 \text { (media } \\
\text { exposure) }\end{array}$} \\
\hline & B & SE (B) & $\beta$ & Sig. & B & SE (B) & $\beta$ & Sig. & B & SE (B) & $\beta$ & Sig. \\
\hline Sex & -.66 & .88 & -.05 & .45 & -.46 & .82 & -.04 & .58 & -.51 & .83 & -.04 & .54 \\
\hline Age & .02 & .12 & .01 & .89 & .08 & .11 & .05 & .45 & .07 & .11 & .04 & .54 \\
\hline $\begin{array}{l}\text { Academic } \\
\text { Success }\end{array}$ & .28 & .41 & .04 & .50 & .20 & .39 & .03 & .60 & .19 & .39 & .03 & .63 \\
\hline $\begin{array}{l}\text { Fathers' } \\
\text { education }\end{array}$ & .06 & .37 & .01 & .87 & -.06 & .35 & -.01 & .88 & -.06 & .35 & -.01 & .86 \\
\hline $\begin{array}{l}\text { Mothers' } \\
\text { education }\end{array}$ & .18 & .38 & .04 & .65 & .21 & .36 & .05 & .55 & .23 & .36 & .05 & .53 \\
\hline $\begin{array}{l}\text { Family } \\
\text { income }\end{array}$ & .44 & .29 & .11 & .13 & .37 & .27 & .09 & .17 & .38 & .27 & .09 & .17 \\
\hline DASS stress & & & & & -.18 & .09 & -.19 & .07 & -.18 & .09 & -.19 & .07 \\
\hline $\begin{array}{l}\text { DASS } \\
\text { anxiety }\end{array}$ & & & & & .34 & .11 & $.30 * *$ & .003 & .33 & .12 & $.29 * *$ & .005 \\
\hline $\begin{array}{l}\text { DASS } \\
\text { depression }\end{array}$ & & & & & .29 & .09 & $.29 * *$ & .001 & .28 & .09 & $.29 * *$ & .002 \\
\hline ASI & & & & & -.02 & .03 & -.06 & .43 & -.03 & .04 & -.08 & .39 \\
\hline $\begin{array}{l}\text { COVID-19 } \\
\text { media } \\
\text { exposure }\end{array}$ & & & & & & & & & -.04 & .04 & -.07 & .25 \\
\hline $\begin{array}{l}\text { Mean world } \\
\text { syndrome }\end{array}$ & & & & & & & & & .02 & .03 & .06 & .48 \\
\hline
\end{tabular}




\begin{tabular}{|c|c|c|c|c|c|c|c|c|c|c|c|}
\hline \multirow[t]{2}{*}{$\begin{array}{l}\text { Risk } \\
\text { behaviour }\end{array}$} & \multicolumn{3}{|c|}{$\begin{array}{l}\text { Model } 1 \text { (soc.-demo. } \\
\text { characteristics) }\end{array}$} & \multicolumn{4}{|c|}{$\begin{array}{l}\text { Model } 2 \text { (stress, } \\
\text { anxiety and } \\
\text { depression) }\end{array}$} & \multicolumn{4}{|c|}{$\begin{array}{l}\text { Model } 3 \text { (media } \\
\text { exposure) }\end{array}$} \\
\hline & SE (B) & $\beta$ & Sig. & B & SE (B) & $\beta$ & Sig. & B & SE (B) & $\beta$ & Sig. \\
\hline$R^{2}$ & \multicolumn{3}{|l|}{.02} & \multicolumn{4}{|l|}{.16} & \multicolumn{4}{|l|}{.16} \\
\hline $\begin{array}{l}R \text { Square } \\
\text { Change }\end{array}$ & \multicolumn{3}{|l|}{.02} & \multicolumn{4}{|l|}{.13} & \multicolumn{4}{|l|}{.01} \\
\hline Adjusted $R^{2}$ & \multicolumn{3}{|c|}{-.002} & \multicolumn{4}{|l|}{.12} & \multicolumn{4}{|l|}{.12} \\
\hline $\mathrm{df}$ & \multicolumn{3}{|l|}{236} & \multicolumn{4}{|c|}{232} & \multicolumn{4}{|c|}{230} \\
\hline $\mathrm{F}$ & \multicolumn{3}{|l|}{0.91} & \multicolumn{4}{|c|}{4.28} & \multicolumn{4}{|c|}{3.71} \\
\hline $\begin{array}{l}F \text { for } \\
\text { change } \\
\text { in } R^{2}\end{array}$ & \multicolumn{3}{|l|}{0.91} & \multicolumn{4}{|c|}{9.15} & \multicolumn{4}{|c|}{0.89} \\
\hline
\end{tabular}

Note: $p<.05^{*} ; p<.01^{* *} ; p<.001^{* * *}$

\section{Discussion}

Our main hypothesis was that there is a statistically significant correlation between COVID-19 media exposure with anxiety, depression, fear and risky behaviour. Our results demonstrate positive significant correlations between risk behaviour, anxiety, stress, depression, Mean world syndrome and COVID-19 media exposure. Still, our regression model established a significant predictive value of anxiety and depression when risk behavior was explained $(p<.01)$. Our correlation analysis on depression, anxiety and risk behaviour is consistent with a number of studies reporting a similar positive relationship (Birmaher et al., 1996; Armstrong \& Costello, 2002; Agardh et al., 2012; Peltzer \& Pengpid, 2015), as experiencing depressive symptoms often impairs decision making. This is a bilateral relation, because most risk-behaviours tend to be associated with an increased likelihood for the development of depression, and are correlated with the severity of depressive symptomatology, as well as alcohol abuse, smoking, media use, lack of physical activity, risky sexual behaviour, school absenteeism, and sleeping problems (Heger et al., 2014; Bannink et al., 2015). For example, a study by Soleimani et al. (2017) reported that the participants' frequency of suicidal thoughts positively predicted anxiety and depression, while age and self-confidence negatively predicted anxiety and depression. Moreover, having friends that smoked and the strength of suicidal thoughts were established as positive predictors of risky behaviours, with males being at higher risk than females. Handley et al. (2019) reported that neuroticism and tobacco use also made a significant independent contribution to future 
depressive symptoms, while interpersonal support was a protective factor, reducing the odds of next-wave depression by $64 \%$.

Our second hypothesis posed that sociodemographic traits have a significant role in risk behaviour, anxiety and depression in adolescents. Our study did not establish significant effects of the participants' sociodemographic traits for risk behaviour. Research by Fu et al. (2020) reported significant differences in anxiety levels based on the participants' sex, age and monthly income. Similarly, in a study examining COVID-19-related anxiety conducted in Croatia by Korajlija and Jokić-Begić (2020), women were significantly more anxious than men, demonstrated through study findings on higher psychological distress in women by Qiu et al. (2020), as well. Stress levels were also related to age, which was not established in our study (Qiu et al., 2020).

We found that COVID-19 media exposure correlate positively with anxiety and the Mean world syndrome. For example, studies in China and the USA reported $79.3 \%$ of participants felt anxious and scared during the pandemic, while $90 \%$ of US citizens said their life had changed as a result of the COVID-19 outbreak (as cited in Liu \& Liu, 2020). Our results can be explained in light of the Media dependency theory, that during difficult times people tend to rely heavily on guidance from media and other sources, as means of reducing uncertainty and uncontrollable feelings in a crisis (Lowrey, 2004; Mukkamala \& Beck, 2018; Martínez-Rojas et al., 2018; all cited in Liu \& Liu, 2020). A number of studies on the critical public events consequences such as the 9/11 attack (2001), the Boston Marathon (2013) explosion or the outbreak of Ebola (2004) showed that negative media portrayal induced higher levels of posttraumatic stress disorder (Ahern et al., 2004; Bourne et al., 2013; Thompson et al., 2019; Bernstein et al., 2007; Holman \& Silver, 2011; Silver et al., 2013; Hadjistavropoulos et al., 1998; Thompson et al., 2017; Lachlan et al., 2009; Garfin et al., 2015; all cited in Liu \& Liu, 2020). Taha et al. (2013) found uncertainty and uncontrollable feelings were positively related to stress and anxiety, as people actively engaged in information-seeking trying to reduce their anxious feelings (Taha et al., 2013). Still, media exposure and vicarious traumatization through information available on the COVID-19 was far beyond the demand for information, so the relation between media exposure and anxiety needs to be revisited. In similar media studies, the frequency or amount of time using social networking sites was associated with mental health problems in children and adolescents, such as higher psychological distress, poor self-rated mental health, depression and suicidal ideation (Dobrean \& Păsărelu, 2016). Studies also focused on pathological uses of online social networking sites, and Facebook in particular, relating them to deficits in emotion regulation and susceptibility to drug and alcohol addictions, 
somatic symptoms, anxiety, insomnia, social dysfunction and depression (Sampasa-Kanyinga \& Hamilton, 2015; Hormes et al., 2014).

The present study has some limitations. As this is a cross-sectional study, we cannot determine the direction of association between media use and exposure, the Mean world syndrome, risk behaviours and depressive or anxiety symptoms. Therefore, the specific nature of the relation between various media contents and adolescent fears, anxiety, depression or risk behaviour still remains elusive.

\section{Conclusions}

The findings of this study have important social, educational, clinical and practical implications regarding media use and exposure for youth dealing with stress, anxiety, depression, the Mean world syndrome and risk behaviours. Our results on the relation of media use and exposure in children and adolescents should be further investigated in order to enhance their positive development and personal, psychological or emotional traits. However, more research is needed to further examine how risk behaviours, media use and emotional problems cluster among adolescents with the goal of identifying potential shared determinants. Furthermore, this paper emphasizes the role of screening for depressive symptoms evident in adolescents, as such practices could be a useful indicator of a myriad of risk behaviours. Finally, the findings of this study suggest that preventive interventions for risk behaviours and depressive symptoms have to target all vulnerable groups, as well as the family and educational context, because no specific effects were established in relation to sociodemographic characteristics.

\section{References}

Agardh, A., Cantor-Graae, E. \& Östergren, PO. (2012). Youth, Sexual Risk-Taking Behavior, and Mental Health: a Study of University Students in Uganda. Int.J. Behav. Med. 19, 208-216. https://doi.org/10.1007/s12529-011-9159-4

Armstrong, T. D., \& Costello, E. J. (2002). Community Studies on Adolescent Substance Use, Abuse, or Dependence and Psychiatric Comorbidity. Journal of Consulting and Clinical Psychology, 70(6), 1224-1239. https://doi.org/10.1037/0022-006X.70.6.1224

Asmundson, G. J., Abramowitz, J. S., Richter, A. A., \& Whedon, M. (2010). Health anxiety: current perspectives and future directions. Curr Psychiatry Rep, 12(4), 306-312. https://doi.org/10.1007/s11920-010-0123-9

Baker, T. B., Piper, M. E., McCarthy, D. E., Majeskie, M. R., \& Fiore, M. C. (2004). Addiction motivation reformulated: An affective processing model of negative reinforcement. Psychological Review, 111(1), 33-51. https://doi.org/10.1037/0033295x.111.1.33 
Bannink, R., Broeren, S., Heydelberg, J., van't Klooster, E., \& Raat, H. (2015). Depressive symptoms and clustering of risk behaviours among adolescents and young adults attending vocational education: a cross-sectional study. BMC Public Health 15, 396. https://doi.org/10.1186/s12889-015-1692-7

Baumeister, R. F., Vohs, K. D., \& Tice, D. M. (2007). The Strenght Model of SelfControl. Current Directions in Psychological Science, 16(6), 351-355. https://doi. org/10.1111\%2Fj.1467-8721.2007.00534.x

Birmaher, B., Ryan, N. D., Williamson, D. E., Brent, D. A., Kaufman, J., Dahl, R. E., Perel, J. \& Nelson, B. R. N. (1996). Childhood and adolescent depression: a review of the past 10 years. Part I. J. Am. Acad. Child Adolesc. Psychiatry, 35(11), 1427-1439. https://doi.org/10.1097/00004583-199611000-00011

Blakey, S. M., \& Abramowitz, J.S. (2017) Psychological Predictors of Health Anxiety in Response to the Zika Virus. J Clin Psychol Med Settings, 24(3-4), 270-278. https://doi. org/10.1007/s10880-017-9514-y

Busse, H., Buck, C., Stock, C., Zeeb, H., Pischke, C. R., Fialho, P. M. M., Wendt, C., \& Helmer, S. M. (2021). Engagement in Health Risk Behaviours before and during the COVID-19 Pandemic in German University Students: Results of a Cross-Sectional Study. Int $J$ Environ Res Public Health, 18(4), 1410. https://doi.org/10.3390/ijerph18041410

Dobrean, A., \& Păsărelu, C. R. (2016). Impact of Social Media on Social Anxiety: A systematic Review. In F. Durbano \& B. Marchesi (Eds.), New Developments in Anxiety Disorders. IntechOpen. http://dx.doi.org/10.5772/65188

Fu, W., Wang, C., Zou, L., Guo, Y., Lu, Z., Yan, S., \&amp; Mao, J. (2020). Psychological health, sleep quality, and coping styles to stress facing the COVID-19 in Wuhan, China. Transl Psychiatry, 10, 225. https://doi.org/10.1038/s41398-020-00913-3

Gerbner, G. (1998). Cultivation analysis: An overview. Mass Communication and Society, 1, 175-194.

Gerbner, G., Gross, L., Jackson-Beeck, M., Jeffries-Fox, S., \& Signorielli, N. (1978). Cultural Indicators: Violence Profile No. 9. Journal of Communication, 28(3), 176-207. https://doi.org/10.1111/j.1460-2466.1978.tb01646.x

Handley, T. E., Rich, J., Lewin, T. J., \& Kelly, B. J. (2019). The predictors of depression in a longitudinal cohort of community dwelling rural adults in Australia. Soc Psychiatry Psychiatr Epidemiol, 54(2), 171-180. doi: https://doi.org/10.1007/s00127-018-1591-1

Heger, J. P., Brunner, R., Parzer, P., Fischer, G., Resch, F., \& Kaess, M. (2014). Depression und Risikoverhalten bei Jugendlichen [Depression and risk behavior in adolescence]. Prax Kinderpsychol Kinderpsychiatr, 63(3), 177-199. http://dx.doi.org/10.13109/ prkk.2014.63.3.177

Hormes, J. M., Kearns, B., \& Timko, C. A. (2014). Craving Facebook? Behavioral addiction to online social networking and its association with emotion regulation deficits. Addiction, 109(12), 2079-2088. https://doi.org/10.1111/add.12713

Klinkenberg, E. (2015). Exploration of the 'Mean World Syndrome' in Dutch Older Persons, VU University Amsterdam, available at: https://www.academia.edu/28815807/ Exploration_of_the_Mean_World_Syndrome_in_Dutch_Older_Persons

Korajlija, A. L., \& Jokić-Begić, N. (2020). COVID-19: Concerns and behaviours in Croatia. British Journal of Health Psychology, 25(4), 849-855. https://doi.org/10.1111/bjhp.12425

Liu, C., \& Liu, Y. (2020). Media Exposure and Anxiety during COVID-19: The Mediation Effect of Media Vicarious Traumatization. International journal of environmental research and public health, 17(13), 4720. https://doi.org/10.3390/ijerph17134720 
Loewenstein, G. F., Weber, E. U., Hsee, C. K., \& Welch, N. (2001). Risk as feelings. Psychological Bulletin, 127(2), 267-286. https://doi.org/10.1037/0033-2909.127.2.267

Lovibond, S.H., \& Lovibond, P.F. (1995). Manual for the Depression Anxiety \& Stress Scales. Psychology Foundation.

Moffitt, T. E., Caspi, A., Harrington, H., \& Milne, B. J. (2002). Males on the lifecourse-persistent and adolescence-limited antisocial pathways: Follow-up at age 26 years. Development and Psychopathology, 14(1), 179-207. https://doi.org/10.1017/ s0954579402001104

Mohammadi, M. R., Zarafshan, H., Bashi, S. K., \& Khaleghi, A. (2020). How to Assess Perceived Risks and Safety Behaviors Related to Pandemics: Developing the Pandemic Risk and Reaction Scale during the COVID-19 Outbreak. Iranian journal of psychiatry, 15(4), 274-285. https://doi.org/10.18502/ijps.v15i4.4293

Peltzer, K., \& Pengpid, S. (2015) Depressive symptoms and social demographic, stress and health risk behaviour among university students in 26 low-, middleand high-income countries. International Journal of Psychiatry in Clinical Practice, 19(4), 259-265. https:// doi.org/10.3109/13651501.2015.1082598

Qiu, J., Shen, B., Zhao, M., Wang, Z., Xie, B., \& Xu, Y. (2020). A nationwide survey of psychological distress among Chinese people in the COVID-19 epidemic: implications and policy recommendations. General Psychiatry, 33, e100213. http://dx.doi.org/10.1136/ gpsych-2020-100213

Reiss, S., Peterson, R. A., Gursky, D. M., \& McNally, R. J. (1986). Anxiety sensitivity, anxiety frequency and the prediction of fearfulness. Behaviour Research and Therapy, 24(1), 1-8. https://doi.org/10.1016/0005-7967(86)90143-9

Reynolds, E. K., Schreiber, W. M., Geisel, K., MacPherson, L., Ernst, M., \& Lejuez, C. W. (2013). Influence of social stress on risk-taking behavior in adolescents. Journal of anxiety disorders, 27(3), 272-277. https://doi.org/10.1016/j.janxdis.2013.02.010

Saladino, V., Algeri, D., \& Auriemma, V. (2020). The Psychological and Social Impact of COVID-19: New Perspectives of Well-Being. Front. Psychol. 11, 577684. https://doi. org/10.3389/fpsyg.2020.577684

Sampasa-Kanyinga, H., \& Hamilton, H. A. (2015). Social networking sites and mental health problems in adolescents: the mediating role of cyberbullying victimization. Eur Psychiatry, 30(8), 1021-1027. https://doi.org/10.1016/j.eurpsy.2015.09.011

Soleimani, M. A., Pahlevan Sharif, S., Bahrami, N., Yaghoobzadeh, A., Allen, K. A., \& Mohammadi, S. (2017). The relationship between anxiety, depression and risk behaviors in adolescents. Int J Adolesc Med Health, 31(2). https://doi.org/10.1515/ijamh-2016-0148

Sourander, A., Jensen, P., Davies, M., Elonheimo, H., Helenius, H., Piha, J., \& Kumpulainen K. (2007). Who is at greatest risk for adverse long-term outcomes? The Finnish From a Boy to a Man study. Journal of the American Academy of Child \& Adolescent Psychiatry, 46(9), 1148-1161. https://doi.org/10.1097/chi.0b013e31809861e9

Taha, S. A., Matheson, K., \& Anisman, H. (2013). H1N1 was not all that scary: Uncertainty and stressor appraisals predict anxiety related to a coming viral threat. Stress Health, 30(2), 149-157. https://doi.org/10.1002/smi.2505 